\title{
The Challenge of Sustainable Access to Telemonitoring Tools for People with Diabetes in Europe: Lessons from COVID-19 and Beyond
}

\author{
Pratik Choudhary • Virginia Bellido • Matthijs Graner • \\ Bernd Altpeter · Americo Cicchetti · Isabelle Durand-Zaleski • \\ Finn Børlum Kristensen
}

Received: June 28, 2021 / Accepted: July 26, 2021 / Published online: August 14, 2021

(C) The Author(s) 2021

\begin{abstract}
Telemedicine in diabetes care has been evolving over several years, particularly since the advent of cloud-connected technologies for diabetes management, such as glucose monitoring devices, including continuous glucose monitoring (CGM) systems, that facilitate sharing of
\end{abstract}

\section{P. Choudhary $(\square)$}

Leicester Diabetes Centre (Bloom), Leicester General Hospital, University of Leicester, Leicester, UK

e-mail: pratik.choudhary@leicester.ac.uk

V. Bellido

Department of Endocrinology and Nutrition, Virgen del Rocío University Hospital, Seville, Spain

\section{Graner}

The Ééndiabetes Foundation, Bussum, The

Netherlands

B. Altpeter

Digital Health Groupe and German Institute of Telemedicine, Frankfurt, Germany

\section{A. Cicchetti}

School of Healthcare Systems, Economics and Management, Universita Cattolica del Sacro Cuore, Rome, Italy

\section{Durand-Zaleski}

Santé publique-AP-HP Hôpitaux Universitaires

Henri Mondor (Créteil), Créteil, France

\section{F. B. Kristensen}

Danish Centre for Health Economics (DaCHE), Faculty of Health Sciences, University of Southern Denmark, Odense, Denmark glucose data between people with diabetes and their healthcare professionals in near-real time. Extreme social distancing and shielding in place for vulnerable patients during the COVID-19 pandemic has created both the challenge and the opportunity to provide care at a distance on a large scale. Available evidence suggests that glucose control has in fact improved during this period for people with diabetes who are able to use CGM devices for remote glucose monitoring. The development of telemedicine as part of the standard of care in diabetes faces significant challenges in the European context, particularly in terms of providing consistent and effective care at a distance to large populations of patients while using robust systems that can be supported by large regional and national healthcare services. These challenges include a fragmented approach to healthcare technology assessment and reimbursement, lack of eHealth education and literacy, particularly amongst healthcare professionals, lack of data integration, as well as concerns about electronic health records, patient consent and privacy. Here we review the benefits of and challenges to wider application of telemedicine and telemonitoring in the post-pandemic future, with the aim to ensure that the value of these eHealth services is provided to patients, healthcare providers and health systems. 
Keywords: eHealth; Telemonitoring; Type diabetes; Continuous COVID-19

\section{Key Summary Points}

The move towards telemedicine as part of diabetes care has been accelerated as a consequence of the COVID-19 pandemic.

Remote glucose-sensing technologies have enabled effective glucose control for adults and children with type 1 diabetes mellitus that is not inferior to standard care pre-COVID.

Evidence shows that adults and children with diabetes are able to engage with their healthcare professional via telemonitoring and receive significant healthcare-related quality of life benefits.

Telemedicine and telemonitoring can improve patient autonomy to manage their diabetes.

Healthcare systems across Europe should support sustainable and broad access to continuous glucose monitoring systems and the remote monitoring solutions associated with them.

Challenges for eHeath include: patient privacy and data ownership; cybersecurity; access to and interoperability of eHealth technologies; incentivisation for providers and health systems; and legal and commercial frameworks specific to eHealth that serve to protect all stakeholders in eHealth.

\section{INTRODUCTION}

Since the global coronavirus disease 2019 (COVID-19) pandemic was declared in March 2020 it has been well-documented that people with diabetes are at higher risk of more severe outcomes with COVID-19, including death [1-3]. This higher risk has been quantified in more detail across several key studies, from which it can be concluded that people with diabetes are over-represented among laboratoryconfirmed COVID-19 cases by 2.3 fold [4] and that they are more than twice as likely to become hospitalised with COVID-19 [2, 5]. Critically, compared with people without diabetes, those with type 1 diabetes (T1DM) or type 2 diabetes (T2DM) were found to have a 3.5and 2.03-fold increased risk, respectively, of dying in hospital with COVID-19 [6, 7]. When adjusted for previous hospital admissions with coronary heart disease, cerebrovascular disease or heart failure, these increased risks for dying in hospital after contracting COVID-19 were 2.86 and 1.81 in people with T1DM and T2DM, respectively. A separate analysis of COVID-19related hospitalisation and mortality of people with diabetes in Scotland indicated an increased odds ratio for critical care or death of 2.4 for those with T1DM and 1.37 for those with T2DM [8]. Along with other socio-economic associations, these increased risks were emphasised in those with higher glucose at admission and poorer glycaemic control as measured by glycated haemoglobin $(\mathrm{HbA} 1 \mathrm{c})[6,9]$. People with T1DM and HbA1c $\geq 86 \mathrm{mmol} / \mathrm{mol}(10 \%)$ had a 2.23-fold increased risk of mortality compared to those with an $\mathrm{HbA} 1 \mathrm{c}$ of $48-53 \mathrm{mmol} / \mathrm{mol}$ (6.5-7.0\%). People with T2DM had a 1.61-fold increased risk of mortality with HbA1c levels $>85 \mathrm{mmol} / \mathrm{mol}(10 \%)$ compared to those with $\mathrm{HbA} 1 \mathrm{c}$ of $48-53 \mathrm{mmol} / \mathrm{mol}(6.5-7.0 \%)$.

Together, these insights confirmed the need for healthcare services and professional societies to recommend a strategy of comprehensive care that allows social distancing for people with diabetes, along with the reorganisation of diabetes services to provide advice and support at a distance, whilst striving to provide active care for people with diabetes at high risk. This ultimately has meant using telemedicine and digital services for consultations, self-management and remote monitoring [10]. In this context, telemedicine encompasses the diverse aspects of using technology to deliver medical care at a distance and may involve telemonitoring, teleexpertise, tele-assistance, tele-visit, tele- 
consultation and tele-education (see Table 1). The goal of diabetes care at a distance, using telemedicine protocols and realising the benefits of sensor-augmented care for monitoring and managing glycaemic control, has been a developing concept since well before the current COVID-19 public health emergency. This is particularly true for people with T1DM, where a range of platforms already exist for downloading and sharing glucose monitoring data as part of routine care. This makes sharing data as part of telemedicine straightforward. Equally, the wider need for eHealth innovation has been the focus of a recent think tank from the European Institute of Innovation and Technology (EIT) [11]. However, the pandemic has put telemedicine in diabetes to the test in new and unexpected ways, as well as revealed the benefits that it can provide; in addition, it has highlighted barriers that must be overcome before telemedicine can become part of standard diabetes care. In capitalising on these insights, we must draw attention to several key areas of engagement that must be addressed in a systematic fashion to establish telemedicine as a standard of care for people with diabetes.

Herein we discuss the opportunity and the challenges of telemedicine in diabetes care, including the need for wider access to telemonitoring systems. The unmet needs for sustainable access to telemedicine services include: stronger frameworks across regulatory bodies for more-informed and robust decision-making; efforts to increase digital health literacy amongst healthcare professionals (HCPs) and people with diabetes, as well as reducing digitalhealth inequity; policies that clarify data ownership and ensure cybersecurity and data protection, and; incentivisation for healthcare providers to engage in telemedicine.

This article is based on previously conducted studies and does not contain any new studies with human participants or animals performed by any of the authors.

Table 1 Definitions for terminologies that describe digital health and care at a distance

\begin{tabular}{|c|c|}
\hline & Description \\
\hline eHealth & $\begin{array}{l}\text { The cost-effective and secure use of information and communication technologies in support of health } \\
\text { and health-related fields, including healthcare services, health surveillance, health literature and health } \\
\text { education, knowledge and research }\end{array}$ \\
\hline Telemedicine & $\begin{array}{l}\text { The practice of medicine using technology to deliver care at a distance, whereby a HCP in one location } \\
\text { uses a telecommunications infrastructure to deliver medical care to a patient at a distant } \\
\text { site. Telemedicine may involve synchronous or asynchronous consultation using information and } \\
\text { communication technology. The scope of telemedicine includes: telemonitoring (see below), tele- } \\
\text { expertise, tele-assistance, tele-visit, teleconsultation and tele-education }\end{array}$ \\
\hline Telemonitoring & $\begin{array}{l}\text { The use of information and communication technology to monitor, transmit and share information } \\
\text { between geographically separated individuals that relates to the health status of a patient. Telemedicine } \\
\text { allows care of patients at home or at other locations remote from their HCPs, using external } \\
\text { telecommunication devices and infrastructure, such as mobile phones and tablet computers, desktop } \\
\text { computers, using broadband or digital cellular networks. The use of CGM systems to monitor glycaemic } \\
\text { metrics is an example of telemonitoring }\end{array}$ \\
\hline mHealth & $\begin{array}{l}\text { Mobile health is a subsegment of eHealth by which medical and public health practices are directly } \\
\text { supported by mobile devices. It particularly includes the use of mobile communications devices for } \\
\text { delivering health and well-being information and services, as well as mobile health applications. } \\
\text { Smartphone apps for reading and reporting glucose-sensor data are established examples of mHealth }\end{array}$ \\
\hline
\end{tabular}

CGM Continuous glucose monitoring, HCP healthcare professional 


\section{THE SUCCESS OF SENSOR- AUGMENTED CARE AND TELEMONITORING IN DIABETES}

Numerous studies have proven the significant clinical benefits of continuous glucose monitoring (CGM) in people with T1DM or T2DM, including reductions in long-term $\mathrm{HbA} 1 \mathrm{c}$ and lower frequency of hypoglycaemia [12-18]. A consequence of the global COVID-19 pandemic is that large-scale solutions for diabetes care at a distance have been put under the spotlight and to the test. People with T1DM or T2DM have had limited or no access to their established diabetes clinical services. Meters or devices that connect to the cloud, such as CGM and flash glucose monitoring devices, have allowed people with diabetes to share their glucose data with their HCPs without the need for in-clinic attendance, which can facilitate objective discussion of glucose results to guide treatment adjustment. Since the first mandated social lockdowns, a series of studies have assessed the efficacy of these tools as enablers of diabetes management at a distance. These include studies in Scotland [19], Spain [20] and France [21] following 572, 307 and 1378 adults with T1DM, respectively, using the FreeStyle Libre system (Abbott Laboratories, Alameda, CA, USA), with data covering the periods before and during lockdown. In the first two studies, percent time in range (\%TIR) $70-180 \mathrm{mg} / \mathrm{dL}(3.9-10 \mathrm{mmol} /$ $\mathrm{L})$, over this period increased, with associated improvements in glycaemic variability and estimated HbA1c (eA1c), and in the third study average glucose decreased. Further studies on smaller groups of people with T1DM across Europe using a range of CGM systems have typically shown improvements in \%TIR and average glucose during enforced social distancing [22-24], including for children and adolescents $[25,26]$, and either improvement or no change in percent time in hypoglycaemia over the same period, including for groups at higher risk of hypoglycaemia $[27,28]$. These data are further supported by an analysis of de-identified data from 65,067 users of the Dexcom G6 CGM system (DexCom, Inc., San Diego, CA, USA) in the USA, which also showed an improvement in $\%$ TIR during the period of stay-at-home [29]. It must be noted that the improvements in glucose levels seen in these studies are multifactorial, but the ability to share and review data in the cloud with HCPs may have been a contributory factor.

\section{THE REALITY OF TELEMEDICINE, TELEMONITORING AND MHEALTH IN DIABETES}

The use of technologies such as CGM, continuous subcutaneous insulin infusion (CSII) and sensor-augmented pumps to provide care remotely has led to the evolution of distinct disciplines that support this 21st century branch of medicine (see Table 1). The value and capability of telemonitoring technology in diabetes is demonstrated by the outcomes of users of CGM systems during the COVID-19 pandemic, as discussed above and illustrated in Fig. 1.

Telemedicine as defined in Table 1 has been validated in a range of settings, including in T1DM and T2DM, that have tested solutions as diverse as smartphone apps for remote insulindosing support [30] to advanced virtual diabetes clinic (VDC) concepts [31]. In each case, the telemedicine approach resulted in significant improvements in HbA1c for people with T1DM [30] or T2DM [31], compared to usual care, along with patient-reported satisfaction with telemedicine [32] and reductions in diabetesrelated distress [33]. A meta-analysis of telemedicine in T1DM and T2DM, covering interventions in $>3000$ participants [34], concluded that telemedicine interventions are at least as effective as usual care in managing diabetes, especially T2DM. In this context, older patients and a longer duration of intervention predict the best outcomes. Notably, a global survey on the use and perception of telemedicine in people with T1DM during the COVID-19 pandemic found that, based on their positive experience, $75 \%$ of those surveyed indicated that they would continue with remote appointments in the future [35]. 

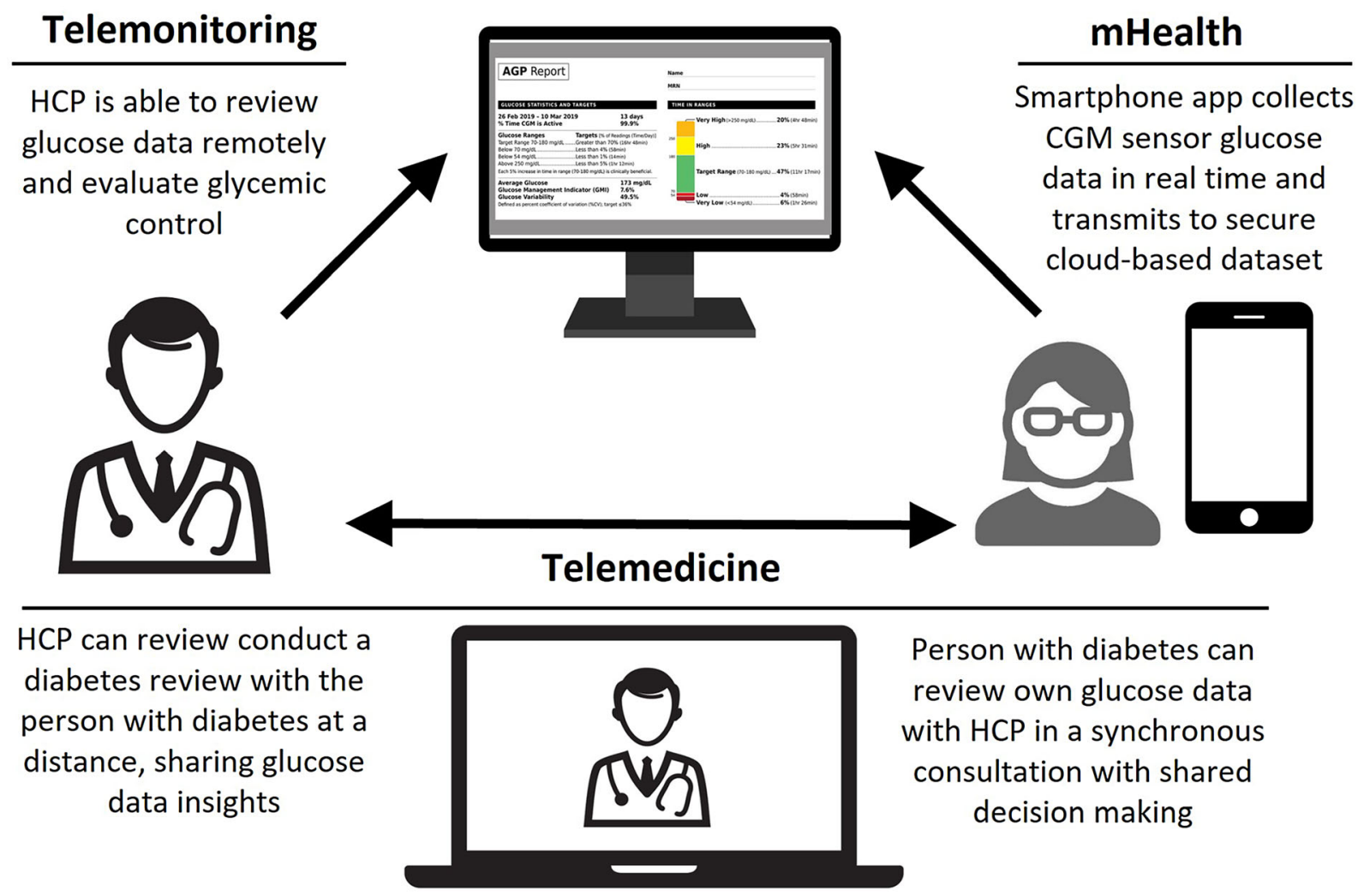

Fig. 1 Successful integration of mHealth, telemonitoring and telemedicine in diabetes. CGM Continuous glucose monitoring, HCP healthcare professional, $m$ Health mobile health

A move to telemedicine has been examined in a number of pediatric diabetes situations, such as the VIDIKI study [36, 37]. However, the concept has most effectively been validated by a successful switch to telemedicine during COVID-19, in which one clinic reported that $>$ $80 \%$ of scheduled visits were accomplished by telemedicine [38], with fewer missed appointments. A separate prospective study of a COVID-safe paediatric telemedicine workflow [39] found that \%TIR and percent time above range (\%TAR) significantly improved in children with T1DM, whilst percent time below range (\%TBR) did not change, and that psychosocial health improved after 6 months.

Telemonitoring also has benefits for women with diabetes during pregnancy, for whom inperson clinic attendance may be inconvenient. A 2020 meta-analysis of 32 randomised controlled trials (RCTs), showed that telemedicine consultations were associated with significant improvements in $\mathrm{HbA1c}$, fasting and postprandial blood glucose [40]. Perinatal and postnatal outcomes, both for mothers and babies, were also improved by telemedicine as compared to standard clinical attendance.

\section{KEY COMPONENTS FOR SUSTAINABLE ACCESS TO TELEMEDICINE SERVICES}

The studies described above confirm that, despite the lack of access to regular in-person diabetes services, glycaemic control does not deteriorate for groups of people with T1DM who are using CGM systems and that it can actually improve in many cases. Furthermore, telemedicine is a proven modality for diabetes management in T1DM, T2DM and diabetes in 
pregnancy. Given that a future return to socalled 'normal' services cannot be predicted or guaranteed, the need for wider application and interpretation of remote glucose monitoring seems clear. This is reflected in a series of international expert panels and recommendations that speak both of the opportunity of diabetes technology application, as well as of the significant challenges [41-43].

As illustrated in Fig. 2, there are many aspects of eHealth that must be aligned for telemedicine to become part of standard of care, encompassing: lack of data integration; eHealth literacy amongst patients and HCPs; healthcare reimbursement systems for digital consultations; as well as concerns about patient consenting, data ownership and privacy in a digital world. The promise of a diabetes digital future confronts us with several unmet needs for action in the near term, which we discuss in the following sections.

\section{HEALTH TECHNOLOGY ASSESSMENT AND TELEMONITORING}

One of the most significant challenges to the development and adoption of telemedicine for effective management of diabetes is the need for appropriate reimbursement. In some cases this may require health technology assessment (HTA) by relevant agencies. HTA has grown over the last decade to provide policy-makers with evidence-based information that is used to formulate healthcare policy and support reimbursement decisions at a national level. In addition to the different levels of development of HTA bodies across European countries, some barriers remain to the adoption of new technologies which limit reimbursement and access to innovations such as remote telemonitoring technologies [44]. In order to ensure long-term, sustainable and equitable access to telemonitoring solutions, more-robust and consistent evaluations are needed, whilst developing the

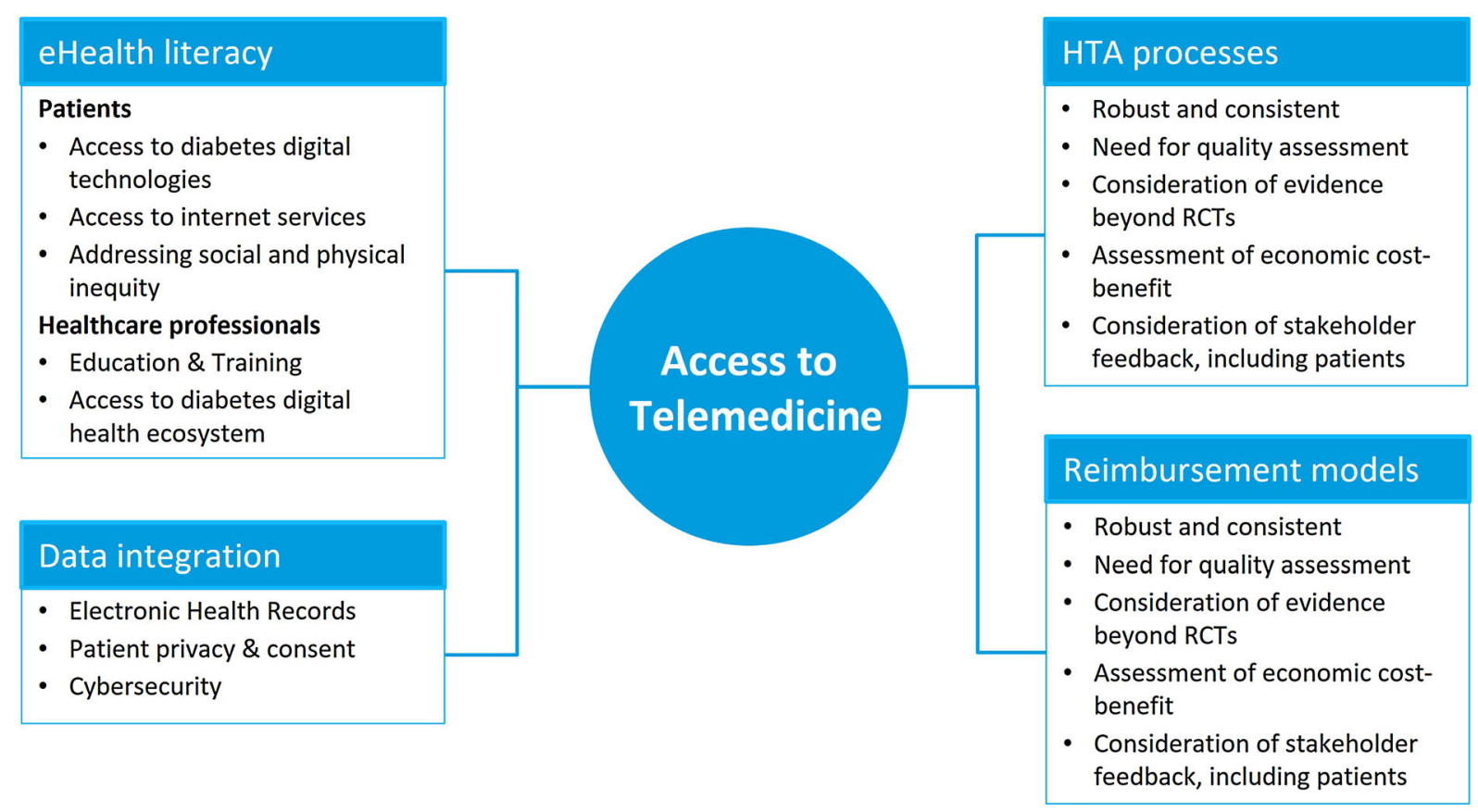

Fig. 2 Key components for sustainable access to telemedicine services. HTA Health technology assessment, RCT randomised clinical trials 
adaptability, flexibility and forward thinking that fosters innovation [11] in separate regions. HTA processes in different countries may have limited abilities to assess and recommend eHealth products, and some HTA agencies may lack internal resources and specific expertise on eHealth, requiring the use of external or joint assessments. Certainly there is a need to increase the capacity of regional HTA bodies so that they are able to deal with the number of assessments that digital health requires within the timeframe needed to undertake review [11]. This increased capacity will avoid delayed approval and reimbursement of eHealth technologies such as remote monitoring solutions and, consequently, digital care. In this context, the 2019 EIT think tank strongly recommended that HTA tools should be fully adapted to the needs of eHealth solutions [11]. This recommendation has implications on whether patients gain access or not to new diabetes technologies, based on geography in some cases, health plans in other cases or even based on diagnosis (e.g. T1DM vs. T2DM).

Assessing the efficacy and cost-effectiveness of a telemonitoring service may require some innovative paradigms as well. Traditional treatment paradigms that focus on patient-level biomedical outcomes evaluated in RCTs may not capture the organisational and system-wide benefits of remote monitoring and telemedicine, with subsequent impacts on workflows, patient and HCP productivity and just-intime treatment paradigms. Real-world evidence can complement trials to measure the full value of the technology in improving disease control, patients' quality of life and work productivity $[11,45,46]$. Paired with the speed of change of the wider technology landscape, where capabilities of existing technologies evolve rapidly, almost on an annual basis, knowledge gained from efficacy trials alone would be rapidly outdated.

A considerable number of HTA organisations exist across Europe, many of which collaborate in the European Network for Health Technology Assessment (EUnetHTA) on joint relative effectiveness assessments (REAs). However, each HTA organisation must take responsibility for making recommendations for stakeholders within their own healthcare jurisdiction and this must reflect their specific regional or national preferences. The impact of these regional variations is significant. A recent analysis of HTA practices across five different healthcare systems in Europe [47] found heterogeneous protocols for the inclusion of studies and variable emphasis on data on clinical efficacy and cost-effectiveness. Similarly, these differences also result in significantly different timeframes for approval and access [48]. Importantly, as telemedicine becomes part of standard care, the separate regional HTA bodies must provide innovators with clear requirements, guidelines and tools that currently apply to the assessment process at a regional level [11].

The choice of assessment criteria is important in the context of telemedicine since the HTA process must evolve to consider objective information from an early stage that is optimally suited to the future application of each device, similar to the renewal of HTAs for drugs each time they are assessed for a new therapeutic indication. The assessment criteria need to include assessment in the context of integrated systems. Areas that have been highlighted for further alignment of HTA methodologies include: the approach to quality assessment; the consideration of early evidence; the type of evidence reviewed outside of RCTs; assessment of the economic case; and consideration of stakeholder feedback [44]. In recognition of this important need, the European Commission has introduced an initiative to strengthen European cooperation on HTAs to improve the speed of access to innovative medical technologies and minimise duplication of work, both for health authorities and for technology manufacturers [49]. This initiative will cover joint clinical assessments, scientific consultation on the clinical development of new products, as well as mapping of emerging health technologies. 


\section{EHEALTH LITERACY IN DIABETES CARE}

\section{Patient eHealth Literacy}

Concerns about a low health literacy of patients translating into poor engagement with eHealth have been documented [50, 51]. However, practical trials and studies have generally shown that people with diabetes respond well to telemedicine and mHealth initiatives, as evidenced in the VDC [33] and VIDIKI studies described above $[36,37]$, with improvements in glycaemic health and health-related quality of life (HRQoL). Patients often prefer face-to-face consultations, since they perceive information to be clearer in this context [52, 53], and the lack of face-to-face interactions is a stated reason for disengaging with eHealth. Thus, telemedicine works best with synchronous rather than asynchronous exchanges, i.e. when patient and HCP are simultaneously involved; thus, the preservation of two-way communication will be a factor in developing appropriate telemedicine solutions. Other themes that emerge from the patient perspective are [52]: (1) generational differences in technology literacy; (2) independence and convenience of remote consultations, (3) sharing of health data and privacy and (4) costs and reliability of technology. The results of the GUIDANCE study [54], a major survey among 7597 patients with T2DM on insulin across eight European nations, indicated that diabetes education appears to be a positive aspect to engagement with telemedicine, alongside improvements in diabetes health metrics.

The use of mHealth applications over online platforms is also endorsed by people with T2DM $[53,55]$, which aligns with the preference for independence and convenience. This includes a preference for reminders and reinforcing messages received by mHealth applications [56]. Overall, telemedicine and mHealth are acceptable in principle for people with diabetes, and there is no implicit problem with health and digital literacy. In fact, digital technologies can help promote diabetes health literacy [54]. However, there is a need for the design of virtual clinics and mHealth solutions to be responsive to the needs of people with diabetes and their expectations.

\section{Social Inequality and eHealth Literacy}

Despite the positive insights on eHealth literacy amongst patients, there is concern that socioeconomic factors, including poverty, as well as impaired motor, visual or auditory capabilities, may have a negative impact on both digital and health literacy. For example, indexes of social deprivation are associated with lower rates of treatment target achievement [57], and people with lower income levels have been shown to have lower engagement with eHealth $[58,59]$. More tellingly, socio-economic deprivation was found to be an independent predictor of a $\geq 5 \%$ decline in \%TIR for people with diabetes during COVID-19-enforced social distancing, despite their use of CGM technology [19]. This is exacerbated by the variation in levels of internet access between different European regions. In $2019,90 \%$ of households across the EU had internet access [60]. However, this encompassed the Netherlands at one end of the scale, with $98 \%$ of internet-enabled households, and Bulgaria at the other end, with only 75\%. Together, these factors mean that achieving the goal of diabetes health equity through improved use of enabling technologies still faces significant barriers [61].

\section{HCP eHealth Literacy}

Similar to the patient experience, the HCP-patient relationship is perceived by HCPs to be at the heart of a successful telemedicine experience $[62,63]$ and is valued for facilitating shared decision-making [64]. However, the use of technology in the care of people with diabetes can create issues when services are not redesigned to accommodate telemedicine [65]. Key areas of concern in this context are: access to technology; support for technology; and the pace of advances.

One of the biggest areas of concern in the European context is the lack of systematic training of HCPs as a workforce in eHealth 
technologies, such as electronic health records (EHR) and telemedicine services. A 2019 survey of 302 medical schools across the $28 \mathrm{EU}$ member states [66] concluded that $<30 \%$ of medical curricula offered eHealth courses and that these were mandatory in only $19 \%$ of medical schools. Of note, the availability of eHealth courses was not correlated with the national GDP per capita, and many of the countries with lower GDP offered a higher rate of eHealth courses to medical students. This trend continues into the clinical phase of medical careers. A 2018 benchmarking survey found that $89 \%$ of primary care physicians across the EU did not engage with telemedicine solutions with their patients, $81 \%$ did not use it with other HCPs and $51 \%$ were either unaware that telemedicine education was available or did not access it [67].

\section{PATIENT DATA-AN IMPORTANT CHALLENGE FOR TELEMONITORING AND TELEMEDICINE}

For people with diabetes, remote consultations can reduce the amount of time and anxiety associated with attending clinic appointments at medical centres. This is accompanied by fewer costs and less inconvenience in terms of taking time off work or school. Despite this, significant barriers to diabetes care at a distance are the long-established norms for patient consenting and privacy that must be preserved within large-scale telemedicine systems. In the small-scale trials and real-world studies that have validated the concept of telemedicine, informed consent of a few hundred patients has been achieved within the scope of each study. However, solutions must be found that will enable HCPs to manage the needs of hundreds of thousands of people with diabetes, with all the dependencies that come with updating EHRs, delivering effective pharmacy and ensuring the involvement of multidisciplinary teams. As previously mentioned, the proof of concept studies on telemedicine have often involved the development of bespoke apps and other solutions for providing VDCs to $<1000$ users. In the real world, we are already facing the need to integrate diabetes data downloads from different devices, as well as to integrate between diabetes devices and EHRs. The EIT insight into medical device innovation specifically identified both technical and legal interoperability as an unmet need for the success of eHealth initiatives within the EU [11]. Ultimately, it is critical that systems are able to operate together and enable large-scale deployment across regional and national healthcare services. A further major issue to consider in this context is cybersecurity, data protection and ownership, as data from blood glucose meters, CGM sensors and CSII systems are increasingly gathered for multiple stakeholders (e.g. patients, HCPs, device manufacturers) [68].

\section{The Need for Consistent EHRs}

With the opportunities provided by telemonitoring, telemedicine and mHealth comes the need for the inclusion and integration of data into a common EHR. This should standardise patient data in easy-to-interpret formats that are compatible with optimal management of patients by multiple clinicians (e.g. a general practitioner and a specialist) and multidisciplinary teams. The EHR should provide an overall understanding of the patient's health status and medical history. Within healthcare services the lack of a unified EHR increases the risk of misdiagnosis and poor healthcare management. For example, the National Health Service in England has implemented policy and technology changes over many years that have created a complex ecosystem of patient EHRs, such that the records of many patients are fragmented between multiple systems and information cannot be effectively shared [69]. The result has been the creation of a common information gap between primary care and secondary care, and between different secondary care institutions.

In recognition of this important barrier to effective telemedicine, the European Commission has made recommendations for a common European EHR exchange format, designed to enable the interoperability of EHRs within and 
between European states [70]. Originally planned for implementation in 2022, the EHR exchange format is intended to improve safe and secure accessibility of health data, allowing for targeted and faster research, diagnosis and treatment [71].

Ensuring data integration is key to providing efficient, patient-centred diabetes management and care. We need data from primary and secondary care to be integrated with patient-generated device data. The need for interoperability between data in EHRs and data on devices will be a key facilitator to an integrated health system. However, this should be accomplished with the purpose of achieving data flow directly into the EHR without the addition of any unnecessary costs or inefficiencies. The intention should be to streamline workflows and enable fully coordinated care, while ensuring all aspects of data ownership, confidentiality, security and privacy are maintained.

\section{Telemedicine and the Business of Optimising eHealth}

The drive towards realising the benefits of eHealth raises important questions that need to be answered with regard to data ownership, cybersecurity, intellectual property management and the legal frameworks that must be developed to support the future landscape of patient data and patient care. eHealth will generate considerable commercial opportunity for businesses able to create and operate a range of efficient and effective decision-support systems that substantially process, quantify and codify huge amounts of healthcare-related data. These will provide integrated tools for diverse healthcare management tasks, such as patient consent and EHR management, scheduling and planning consultations, booking of test procedures, electronic prescribing, reimbursement, patient risk analysis and care-quality audits. The COVID-19 pandemic has highlighted the scale of this opportunity, and investment in digital health has doubled in 2021 compared to 2019 [72].

In the face of this development, there is a need for better defined legal, regulatory and commercial structures to govern this new landscape. Across the EU, the legal frameworks for optimising eHealth have focussed on established directives for the provision of patient care across borders and within data protection laws $[73,74]$. However, these do not address the need for technical and legal interoperability that are acknowledged to underpin the success of eHealth initiatives [11]. Similarly, specific initiatives to define and protect intellectual property related to eHealth and telemedicine products and services are lacking, relying instead on existing patent protection and licensing structures [75]. The COVID-19 pandemic has accelerated the development of systems and structures that emphasise the practice of telemedicine and the value of telemonitoring. In doing so, it has further highlighted the need for specific frameworks to foster the growth of this innovative sector.

\section{REIMBURSEMENT MODELS MUST INCENTIVISE THE BENEFITS OF TELEMEDICINE}

Another consideration is the reimbursement models that are in place to meet the needs of HCPs, institutions and payers with regard to telemedicine. Variability in the approach to reimbursement is epitomised by the variable funding for CGM, which has proven efficacy in lowering HbA1c and reducing hospital admissions for acute diabetes events [18, 45, 76]. Despite this, CGM cost-effectiveness is seen as uncertain by many reimbursement agencies. This is also reflected in reimbursement models that do not compensate physicians for services delivered remotely or that focus only on volume rather than value of telemedicine consultations. This might lead to a lack of financial incentive to drive adoption and use of proven eHealth technologies. COVID-19 has provided the context through which immediate concerns over reimbursement have been temporarily suspended, but in the post-pandemic landscape they must reflect the provision of telemedicine as standard care. This has been spotlighted by the passing in November 2019 of the Digital Healthcare Act in Germany [77], as part of 
promoting the benefits of eHealth solutions. This act encourages HCPs to offer telemedicine consultations and promotes this option to patients. As of 2020, physicians in Germany can prescribe lower-risk digital applications for the monitoring, detection and relief of illnesses, and it is mandated that health insurance companies in Germany must reimburse approved applications, including for diabetes management.

Similarly, the French national insurance body approved reimbursement for telemedicine consultations in February 2019, and in March 2020 these rules were further eased by approving unlimited telemedicine for people with COVID-19 [78]. Consequently, approximately 5.5 million telemedicine consultations were reimbursed in France between March and April 2020, compared to a few thousand each week prior to COVID-19.

Italy is rapidly moving in this direction, since the COVID-19 outbreak has driven an acceleration of the use of telemedicine and telemonitoring for COVID-19 and non-COVID19 patients. In this context, $>200$ new changes were introduced into clinical practice in the 3 months from March 2020 [79]. Under this pressure, the Italian Ministry of Health issued 'National Guidelines for Telemedicine in the NHS' that have been approved by the State-Regions Conference on 17 December 2020, providing indication for reimbursement of telemedicine and telemonitoring solutions. Using these guidelines as a basis, some regions have already approved new tariffs to reimburse telemedicine and telemonitoring services.

The emphasis in the value provided by telemedicine during the pandemic will need to become part of regular healthcare reimbursement practice in all EU countries, just as it has become in France and Germany. A pre-COVID19 analysis by the European Commission found that telemedicine is reported to be cost-effective in $73.3 \%$ of the cases covered by the literature [80]. Once the needs of patient safety, highlighted by the COVID-19 pandemic, are taken into consideration, the case would appear to be compelling.

\section{UNMET NEEDS AND ACTIONS}

The benefits of telemonitoring in diabetes indicate that it can be expected to become an acknowledged standard of care in European countries. This is most evident from the value that has been demonstrated during the COVID19 pandemic. However, there are existing challenges that must be met if implementation of telemedicine across countries in Europe is to be achieved. In meeting these challenges we have identified the following actions that should be taken:

1. EU countries should promote the increase of investment in telemedicine and technology that allow remote monitoring and remote, automated data collection to expand usage of remote monitoring of atrisk patient populations, such as people with diabetes.

2. Regulatory and HTA bodies should develop flexible and adaptive frameworks to evaluate telemonitoring devices that foster innovation and allow countries to make betterinformed and transparent decisions. This should include research data that validate the role of telemedicine and the factors that make it effective in managing different diseases. Once these frameworks are adopted, there should be systematic plans for broad adoption of these evaluation tools and ultimately approvals and reimbursement of telemonitoring devices that allow remote monitoring of insulin and glucose data of proven benefits. Early engagement between HTA bodies and manufacturers should be enhanced, with the aim to accelerate valuable innovation for patients.

3. Regulators and HTA bodies should use realworld data that evaluate benefits to the system as well as the person with diabetes, in order to enhance evidence generation for a quicker and more appropriate assessment of telemedicine innovations. Ultimately, the mandate of HTA bodies should be to promote-rather than to limit-the uptake of telemedicine.

4. Governments in the region should work together to develop clear policies to ensure 
cybersecurity, data protection and datasharing policies across borders to support appropriate access to telemonitoring systems, while also ensuring patient ownership of their data. Government agencies should develop legislation to ensure that all entities, both government and private, take stringent steps to maintain data security, so that only authorised users are able to access data that is relevant to their work.

5. Governments in the region should work on specific plans to ensure that telemonitoring reduces health inequity rather than widening the digital divide. This could be done in multiple ways, including ensuring internet access in remote areas, designing tools to ensure that telemonitoring is accessible to those with motor, visual or hearing impairments and providing subsidies to people who are unable to afford it. This must be part of ensuring that the general population is able to achieve a basic level of technological literacy. In this context, efforts must be made to inform and educate HCP at all stages of medical training on the value of telemedicine in improving delivery of care, including awareness of the latest technology and the essential components of telemedicine. These actions will enable everyone to benefit from eHealth technology, instead of a select few.

6. Payers should consider incentivising HCPs to engage in telemonitoring to promote acceptance and usage of solutions with proven benefits. The ease of use of these devices will encourage their adoption not only by HCPs, but by all patients regardless of their age, which would help to bring the cultural and structural changes needed.

7. Manufacturers should continue to invest in innovation that demonstrates value, as defined by the patient, and is easy to operate, while ensuring data protection, patient privacy and cyber security.

\section{CONCLUSIONS}

The established goal of increased telemedicine as part of diabetes care has been intensified and accelerated as a consequence of the COVID-19 pandemic and the enforced need for extreme social distancing for people with diabetes. Experience and evidence have accumulated that glucose-sensing technologies have enabled effective glycaemic control for adults and children with T1DM that is not inferior to standard care pre-COVID and that for many individuals these technologies have resulted in improved glucose control. The remote availability of glucose data for simultaneous review by people with diabetes and their HCPs supports the efficacy of these technologies as part of organised telemedicine in diabetes in the post-pandemic future. Separate from the enforced needs of the pandemic, there is significant evidence that adults and children with diabetes are willing and able to engage with their HCP using telephone, text and videoconference systems, and that they perceive these to provide significant HRQoL benefits. The use of remote monitoring systems not only complements face-to-face consultations, but is likely to improve patients' autonomy to manage and control their disease [21], thus encouraging their adherence with treatment.

At the present time, it is important for the region and associated stakeholders to ensure that diabetes care policies support sustainable and broad access to CGM systems and the remote monitoring solutions associated with them. These policies need to: (1) ensure a true measure of the value these devices bring to patients, HCPs and the health system in decision-making; (2) protect patient privacy and data, while giving the person with diabetes the option to allow all invested stakeholders to have access and interoperability; (3) bridge healthcare inequities; and (4) incentivise broad adoption by patients, HCPs and health systems. 


\section{ACKNOWLEDGEMENTS}

The work of the author group and the associated 'Call to Action on the Need to Ensure Sustainable and Broad Access to Telemonitoring Tools in People With Diabetes' was coordinated by Fleur Levrat-Guillen from Abbott's Diabetes Care division.

Funding. Support for this work and the journal's Rapid Service Fee was provided by Abbott Diabetes Care.

Medical writing/Editorial Assistance. Editorial assistance in the preparation of this manuscript was provided by Dr Robert Brines of Bite Medical Consulting.

Authorship. All named authors meet the International Committee of Medical Journal Editors (ICMJE) criteria for authorship for this article, take responsibility for the integrity of the work as a whole, and have given their approval for this version to be published.

Authors' Contributions. All authors worked collaboratively to review and prepare the final manuscript. P.C. is the guarantor and takes full responsibility for the work as the whole.

Disclosures. Pratik Choudhary has received personal fees from Abbott, Medtronic, Dexcom, Lilly, Sanofi, Novo Nordisk and Insulet. Isabelle Durand Zaleski has received personal fees for participation in advisory boards for Abbott, Air Liquide, Boston scientific, Medtronic, BMS, MSD, Pfizer, Sanofi and Takeda. Virginia Bellido has received speaker fees and advisory honoraria from Abbott, AstraZeneca, Boehringer Ingelheim, Eli Lilly, Esteve, Janssen, Merck, Mundipharma, Novartis, Novo Nordisk, Roche and Sanofi. Finn Børlum Kristensen has received advisory fees from Abbott. Matthijs Graner, Bernd Altpeter and Americo Cicchetti declare no conflicts of interest.

Compliance with Ethical Guidelines. This article is based on previously conducted studies and does not contain any new studies with human participants or animals performed by any of the authors.

Data Availability. Data sharing is not applicable to this article as no new data sets were generated during the current study.

Open Access. This article is licensed under a Creative Commons Attribution-NonCommercial 4.0 International License, which permits any non-commercial use, sharing, adaptation, distribution and reproduction in any medium or format, as long as you give appropriate credit to the original author(s) and the source, provide a link to the Creative Commons licence, and indicate if changes were made. The images or other third party material in this article are included in the article's Creative Commons licence, unless indicated otherwise in a credit line to the material. If material is not included in the article's Creative Commons licence and your intended use is not permitted by statutory regulation or exceeds the permitted use, you will need to obtain permission directly from the copyright holder. To view a copy of this licence, visit http://creativecommons.org/licenses/by$\mathrm{nc} / 4.0 /$.

\section{REFERENCES}

1. Zhou F, Yu T, Du R, et al. Clinical course and risk factors for mortality of adult inpatients with COVID-19 in Wuhan, China: a retrospective cohort study. Lancet. 2020;395(10229):1054-62.

2. Bode B, Garrett V, Messler J, et al. Glycemic characteristics and clinical outcomes of COVID-19 patients hospitalized in the United States. J Diabetes Sci Technol. 2020;14(4):813-21.

3. Chen Y, Yang D, Cheng B, et al. Clinical characteristics and outcomes of patients with diabetes and COVID-19 in association with glucose-lowering medication. Diabetes Care. 2020;43(7):1399-407.

4. Stokes EK, Zambrano LD, Anderson KN, et al. Coronavirus disease 2019 case surveillance-United States, January 22-May 30, 2020. Morbidity Mortal Wkly Rep. 2020;69(24):759-65.

5. de Almeida-Pititto B, Dualib PM, Zajdenverg L, et al. Severity and mortality of COVID 19 in patients 
with diabetes, hypertension and cardiovascular disease: a meta-analysis. Diabetol Metab Syndr. 2020;12(1):75. https://doi.org/10.1186/s13098-02000586-4.

6. Holman N, Knighton P, Kar P, et al. Risk factors for COVID-19-related mortality in people with type 1 and type 2 diabetes in England: a population-based cohort study. Lancet Diabetes Endocrinol. 2020;8(10):823-33.

7. Barron E, Bakhai C, Kar P, et al. Associations of type 1 and type 2 diabetes with COVID-19-related mortality in England: a whole-population study. Lancet Diabetes Endocrinol. 2020;8(10):813-22.

8. McGurnaghan SJ, Weir A, Bishop J, et al. Risks of and risk factors for COVID-19 disease in people with diabetes: a cohort study of the total population of Scotland. Lancet Diabetes Endocrinol. 2021;9(2):82-93.

9. Carrasco-Sánchez FJ, López-Carmona MD, Martínez-Marcos FJ, et al. Admission hyperglycaemia as a predictor of mortality in patients hospitalized with COVID-19 regardless of diabetes status: data from the Spanish SEMI-COVID-19 Registry. Ann Med. 2020;53(1):103-16.

10. Wake DJ, Gibb FW, Kar P, et al. ENDOCRINOLOGY IN THE TIME OF COVID-19: Remodelling diabetes services and emerging innovation. Eur J Endocrinol. 2020;183(2):G67-77.

11. European Institute of Innovation and Technology (EIT). Future-proofing Europe's digital health innovation pathway. 2019. https://eithealth.eu/wpcontent/uploads/2020/04/EIT_Health_Think_

Tank_PanEU_Report-1.pdf. Accessed 4 Apr 2021.

12. Lind M, Polonsky W, Hirsch IB, et al. Continuous glucose monitoring vs conventional therapy for glycemic control in adults with type 1 diabetes treated with multiple daily insulin injections: the GOLD randomized clinical trial. JAMA. 2017;317: 379-87. https://doi.org/10.1001/jama.2016.19976.

13. Aleppo G, Ruedy KJ, Riddlesworth TD, et al. REPLACE-BG: a randomized trial comparing continuous glucose monitoring with and without routine blood glucose monitoring in adults with wellcontrolled type 1 diabetes. Diabetes Care. 2017;40: 538-45. https://doi.org/10.2337/dc16-2482.

14. Beck RW, Riddlesworth T, Ruedy K, et al. Effect of continuous glucose monitoring on glycemic control in adults with type 1 diabetes using insulin injections: the DIAMOND randomized clinical trial. JAMA. 2017;317:371-8. https://doi.org/10.1001/ jama.2016.19975.
15. Beck RW, Riddlesworth TD, Ruedy K, et al. Continuous glucose monitoring versus usual care in patients with type 2 diabetes receiving multiple daily insulin injections. Ann Intern Med. 2017;167: 365-74. https://doi.org/10.7326/m16-2855.

16. Bolinder J, Antuna R, Geelhoed-Duijvestijn P, Kröger J, Weitgasser R. Novel glucose-sensing technology and hypoglycaemia in type 1 diabetes: a multicentre, non-masked, randomised controlled trial. Lancet. 2016;388(10057):2254-62. https://doi. org/10.1016/s0140-6736(16)31535-5.

17. Haak T, Hanaire H, Ajjan R, Hermanns N, Riveline $\mathrm{J}-\mathrm{P}$, Rayman G. Flash glucose-sensing technology as a replacement for blood glucose monitoring for the management of insulin-treated type 2 diabetes: a multicenter, open-label randomized controlled trial. Diabetes Ther. 2017;8:55-73. https://doi.org/ 10.1007/s13300-016-0223-6.

18. Evans M, Welsh Z, Ells S, Seibold A. The impact of flash glucose monitoring on glycaemic control as measured by HbA1c: a meta-analysis of clinical trials and real-world observational studies. Diabetes Ther. 2019;11:83-95. https://doi.org/10.1007/ s13300-019-00720-0.

19. Dover AR, Ritchie SA, McKnight JA, et al. Assessment of the effect of the COVID-19 lockdown on glycaemic control in people with type 1 diabetes using flash glucose monitoring. Diabetic Med. 2020; . https://doi.org/10.1111/dme.14374.

20. Fernández E, Cortazar A, Bellido V. Impact of COVID-19 lockdown on glycemic control in patients with type 1 diabetes. Diabetes Res Clin Pract. 2020;166: 108348. https://doi.org/10.1016/j. diabres.2020.108348.

21. Potier L, Hansel B, Larger E, et al. Stay-at-home orders during the COVID-19 pandemic, an opportunity to improve glucose control through behavioral changes in type 1 diabetes. Diabetes Care. 2020;44(3):839-43.

22. Bonora BM, Boscari F, Avogaro A, Bruttomesso D, Fadini GP. Glycaemic control among people with type 1 diabetes during lockdown for the SARS-CoV2 outbreak in Italy. Diabetes Ther. 2020;11(6): 1369-79.

23. Aragona M, Rodia C, Bertolotto A, et al. Type 1 diabetes and COVID-19: the "Lockdown effect." Diabetes Res Clin Pract. 2020;170:108468. https:// doi.org/10.1016/j.diabres.2020.10846.

24. Capaldo B, Annuzzi G, Creanza A, et al. Blood glucose control during lockdown for COVID-19: CGM metrics in Italian adults with type 1 diabetes. Diabetes Care. 2020;43(8):e88-9. https://doi.org/10. 2337/dc20-1127. 
25. Marigliano M, Maffeis C. Glycemic control of children and adolescents with type 1 diabetes improved after COVID-19 lockdown in Italy. Acta Diabetol. 2021;58(5):661-4.

26. Schiaffini R, Barbetti F, Rapini N, et al. School and pre-school children with type 1 diabetes during Covid-19 quarantine: the synergic effect of parental care and technology. Diabetes Res Clin Pract. 2020;166: 108302. https://doi.org/10.1016/j. diabres.2020.108302.

27. Maddaloni E, Coraggio L, Pieralice S, Carlone A, Pozzilli P, Buzzetti R. Effects of COVID-19 lockdown on glucose control: continuous glucose monitoring data from people with diabetes on intensive insulin therapy. Diabetes Care. 2020;43(8):e86-7. https:// doi.org/10.2337/dc20-0954.

28. Mesa A, Viñals C, Pueyo I, et al. The impact of strict COVID-19 lockdown in Spain on glycemic profiles in patients with type 1 diabetes prone to hypoglycemia using standalone continuous glucose monitoring. Diabetes Res Clin Pract. 2020;167: 108354. https://doi.org/10.1016/j.diabres.2020. 108354.

29. van der Linden J, Welsh JB, Hirsch IB, Garg SK. RealTime continuous glucose monitoring during the coronavirus disease 2019 pandemic and its impact on time in range. Diabetes Technol Ther. 2021;23(S1):S-1-S-7.

30. Charpentier G, Benhamou P-Y, Dardari D, et al. The diabeo software enabling individualized insulin dose adjustments combined with telemedicine support improves HbA1c in poorly controlled type 1 diabetic patients. Diabetes Care. 2011;34(3): 533-9.

31. Dixon RF, Zisser H, Layne JE, et al. A virtual type 2 diabetes clinic using continuous glucose monitoring and endocrinology visits. J Diabetes Sci Technol. 2020;14(5):908-11.

32. Bergenstal RM, Layne JE, Zisser H, et al. Remote application and use of real-time continuous glucose monitoring by adults with type 2 diabetes in a virtual diabetes clinic. Diabetes Technol Ther. 2020;23:128-32. https://doi.org/10.1089/dia.2020. 0396.

33. Polonsky WH, Layne JE, Parkin CG, et al. Impact of participation in a virtual diabetes clinic on diabetesrelated distress in individuals with type 2 diabetes. Clin Diabetes. 2020;38(4):357-62.

34. Tchero H, Kangambega P, Briatte C, Brunet-Houdard S, Retali GR, Rusch E. Clinical effectiveness of telemedicine in diabetes mellitus: a meta-analysis of 42 randomized controlled trials. Telemed J eHealth. 2019;25(7):569-83.
35. Scott SN, Fontana FY, Züger T, Laimer M, Stettler C. Use and perception of telemedicine in people with type 1 diabetes during the COVID-19 pandemicresults of a global survey. Endocrinol Diabetes Metab. 2021;4(1):e00180. https://doi.org/10.1002/ edm2.180.

36. von Sengbusch S, Eisemann N, Mueller-Godeffroy $\mathrm{E}$, et al. Outcomes of monthly video consultations as an add-on to regular care for children with type 1 diabetes: a 6-month quasi-randomized clinical trial followed by an extension phase. Pediatr Diabetes. 2020;21(8):1502-15.

37. von Sengbusch S, Doerdelmann J, Lemke S, et al. Parental expectations before and after 12-month experience with video consultations combined with regular outpatient care for children with type 1 diabetes: a qualitative study. Diabet Med. 2020. https://doi.org/10.1111/dme.14410.

38. March CA, Flint A, DeArment D, et al. Paediatric diabetes care during the COVID-19 pandemic: Lessons learned in scaling up telemedicine services. Endocrinol Diabetes Metab. 2021;4(1):e00202. https://doi.org/10.1002/edm2.202.

39. Braune K, Boss K, Schmidt-Herzel J, et al. Shaping workflows in digital and remote diabetes care during the COVID-19 pandemic: a service design approach. JMIR Mhealth Uhealth. 2020;9(4): e24374. https://doi.org/10.2196/24374.

40. Xie W, Dai P, Qin Y, Wu M, Yang B, Yu X. Effectiveness of telemedicine for pregnant women with gestational diabetes mellitus: an updated metaanalysis of 32 randomized controlled trials with trial sequential analysis. BMC Pregnancy Childb. 2020;20(1):198. https://doi.org/10.1186/s12884020-02892-1.

41. Han J, King F, Klonoff D, et al. Digital diabetes congress 2019. J Diabetes Sci Technol. 2019;13(5): 979-89.

42. Phillip M, Bergenstal RM, Close KL, et al. The Digital/Virtual Diabetes Clinic: the future is nowrecommendations from an International Panel on Diabetes Digital Technologies Introduction. Diabetes Technol Ther. 2020;23:146-54. https://doi. org/10.1089/dia.2020.0375.

43. Medtech Europe. From diagnosis to cure: a vision for digitally enabled care in Europe. 2020. https:// www.medtecheurope.org/resource-library/a-visionfor-digitally-enabled-diabetes-care-in-europe. Accessed 4 Apr 2021

44. Levrat-Guillen F, Blissett D, Beckerman R, Saborido $\mathrm{CM}$, Benhamou P-Y. The role of Health Technology Assessment in the adoption of new technologies in 
diabetes care: a review of HTA reports on FreeStyle Libre. Pharmacoeconomics. 2019;4:122.

45. Charleer S, Mathieu C, Nobels F, et al. Effect of continuous glucose monitoring on glycemic control, acute admissions, and quality of life: a realworld study. J Clin Endocrinol Metab. 2018;103(3): 1224-32.

46. Fokkert $M$, van Dijk $P$, Edens $M$, et al. Improved well-being and decreased disease burden after 1-year use of flash glucose monitoring (FLARENL4). BMJ Open Diabetes Res Care. 2019;7(1): e000809. https://doi.org/10.1136/bmjdrc-2019000809 .

47. Vreman RA, Mantel-Teeuwisse AK, Hövels AM, Leufkens HGM, Goettsch WG. Differences in health technology assessment recommendations among European jurisdictions: the role of practice variations. Value Health. 2020;23(1):10-6.

48. Armoiry X, Spath H-M, Clarke A, Connock M, Sutcliffe P, Dussart C. Comparison of health technology assessment for new medicines in France and England: an example based on ixazomib for patients with relapsed or refractory multiple myeloma. J Market Access Health Policy. 2019;7(1): 1648971. https://doi.org/10.1080/20016689.2019. 1648971.

49. European Commission. Health technology assessment. https://ec.europa.eu/health/technology_ assessment/overview_en. Accessed 4 Apr 2021.

50. Mackert M, Mabry-Flynn A, Champlin S, Donovan EE, Pounders K. Health literacy and health information technology adoption: the potential for a new digital divide. J Med Internet Res. 2016;18(10): e264. https://doi.org/10.2196/jmir.6349.

51. Dunn P, Hazzard E. Technology approaches to digital health literacy. Int J Cardiol. 2019;293: 294-6.

52. Lee JY, Chan CKY, Chua SS, et al. Using telemedicine to support care for people with type 2 diabetes mellitus: a qualitative analysis of patients' perspectives. BMJ Open. 2019;9(10):e026575. https://doi.org/10.1136/bmjopen-2018-026575.

53. Buysse H, Coremans P, Pouwer F, Ruige J. Sustainable improvement of HbA1c and satisfaction with diabetes care after adding telemedicine in patients on adaptable insulin regimens: Results of the TeleDiabetes randomized controlled trial. Health Inform J. 2020;26(1):628-41.

54. Boels AM, Vos RC, Hermans TGT, et al. What determines treatment satisfaction of patients with type 2 diabetes on insulin therapy? An observational study in eight European countries. BMJ
Open. 2017;7(7):e016180. https://doi.org/10.1136/ bmjopen-2017-016180.

55. Rodríguez-Fortúnez P, Franch-Nadal J, Fornos-Pérez JA, Martínez-Martínez F, de Paz HD, Orera-Peña ML. Cross-sectional study about the use of telemedicine for type 2 diabetes mellitus management in Spain: patient's perspective. The EnREDa2 Study. BMJ Open. 2019;9(6):e028467. https://doi.org/10.1136/ bmjopen-2018-028467.

56. Torbjørnsen A, Ribu L, Rønnevig M, Grøttland A, Helseth S. Users' acceptability of a mobile application for persons with type 2 diabetes: a qualitative study. BMC Health Serv Res. 2019;19(1):641. https://doi.org/10.1186/s12913-019-4486-2.

57. NHS Digital. National Diabetes Audit 2018-2019, England and Wales. 2010. https://files.digital.nhs. uk/C3/BA598C/REF161\%20National\%20Diabetes\% 20Audit\%202018-19\%20Full\%20Report\%201\% 2C\%20Care\%20Processes $\% 20$ and $\% 20$ Treatment $\%$ 20Targets.pptx. Accessed 4 Apr 2021.

58. Sun R, Burke LE, Saul MI, Korytkowski MT, Li D, Sereika SM. Use of a patient portal for engaging patients with type 2 diabetes: patterns and prediction. Diabetes Technol Ther. 2019;21(10):546-56.

59. Reed ME, Huang J, Graetz I, et al. Patient characteristics associated with choosing a telemedicine visit vs office visit with the same primary care clinicians. JAMA Netw Open. 2020;3(6): e205873. https://doi.org/10.1001/jamanetworkopen.2020. 5873.

60. Eurostat. Digital economy and society statistics-households and individuals. 2020. https://ec. europa.eu/eurostat/statistics-explained/index.php/ Digital_economy_and_society_statistics_households_and_individuals\#Internet_access. Accessed 18 Mar 2021.

61. Azzopardi-Muscat N, Sørensen K. Towards an equitable digital public health era: promoting equity through a health literacy perspective. Eur J Public Health. 2019;29(Suppl 3):13-7.

62. Lie SS, Karlsen B, Graue M, Oftedal B. The influence of an eHealth intervention for adults with type 2 diabetes on the patient-nurse relationship: a qualitative study. Scand J Caring Sci. 2019;33(3):741-9.

63. Ronda MCM, Dijkhorst-Oei L-T, Vos RC, Rutten GEHM. Diabetes care providers' opinions and working methods after four years of experience with a diabetes patient web portal; a survey among health care providers in general practices and an outpatient clinic. BMC Fam Pract. 2018;19(1):94. https://doi.org/10.1186/s12875-018-0781-y. 
64. Thomson K, Brouwers C, Damman OC, de Bruijne MC, Timmermans DR, Melles M. How health care professionals evaluate a digital intervention to improve medication adherence: qualitative exploratory study. JMIR Hum Factors. 2018;5(1):e7. https://doi.org/10.2196/humanfactors.8948.

65. James S, Perry L, Gallagher R, Lowe J. Diabetes educators. J Diabetes Sci Technol. 2016;10(5): 1115-21.

66. Giunti G, Guisado-Fernandez E, Belani H, LacalleRemigio JR. Mapping the access of future doctors to health information technologies training in the European Union: cross-sectional descriptive study. J Med Internet Res. 2019;21(8): e14086. https://doi. org/10.2196/14086.

67. European Commission. Benchmarking deployment of eHealth among general practitioners. 2018. https://ec.europa.eu/newsroom/dae/document. cfm?doc_id=60210. Accessed 4 Apr 2021.

68. Shang T, Zhang JY, Klonoff DC. The FDA pilot accreditation scheme for conformity: will it pertain to cybersecurity of diabetes devices? J Diabetes Sci Technol. 2021;15(3):535-8. https://doi.org/10. $1177 / 1932296821997915$.

69. Warren LR, Clarke J, Arora S, Darzi A. Improving data sharing between acute hospitals in England: an overview of health record system distribution and retrospective observational analysis of inter-hospital transitions of care. BMJ Open. 2019;9(12): e031637. https://doi.org/10.1136/bmjopen-2019031637.

70. European Commission. Commission recommendation on a European electronic health record exchange format. 2019. https://ec.europa.eu/ newsroom/dae/document.cfm?doc_id=57254. Accessed 4 Apr 2021.

71. European Commission. Shaping Europe's digital future. 2020. https://ec.europa.eu/info/sites/info/ files/communication-shaping-europes-digitalfuture-feb2020_en_4.pdf. Accessed 4 Apr 2021.

72. Bestsennyy O, Gilbert G, Harris A, Rost J. Telehealth: A quarter trillion-dollar post-COVID-19 reality? McKinsey \& Company. 2021. https://www. mckinsey.com/industries/healthcare-systems-andservices/our-insights/telehealth-a-quarter-trilliondollar-post-covid-19-reality. Accessed 23 July 2021.
73. The European Parliament and the Council of the Europeans Union. Directive 2011/24/EU of the European Parliament and of the Council of 9 March 2011 on the application of patients' rights in crossborder healthcare. OJEU. 2011;88:45-65. http:// data.europa.eu/eli/dir/2011/24/oj. Accessed 22 July 2021.

74. European Commission. Proposal for a Regulation of the European Parliament and of the Council on the protection of individuals with regard to the processing of personal data and on the free movement of such data (General Data Protection Regulation)/ COM/2012/011 final-2012/0011. http://eur-lex. europa.eu/legal-content/en/ALL/?uri=CELEX: 52012PC0011. Accessed 22 July 2021.

75. World Trade Organization, World Health Organization and World Intellectual Property Organization. Promoting access to medical technologies and innovation. Geneva; 2020. http://www.wipo.int/ edocs/pubdocs/en/wipo_pub_628_2020.pdf. Accessed 22 July 2021.

76. Bergenstal RM, Kerr MSD, Roberts GJ, Souto D, Nabutovsky Y, Hirsch IB. Flash CGM is associated with reduced diabetes events and hospitalizations in insulin-treated type 2 diabetes. J Endocr Soc. 2021;5(4):bvab013. https://doi.org/10.1210/jendso/ bvab013.

77. Gerke S, Stern AD, Minssen T. Germany's digital health reforms in the COVID-19 era: lessons and opportunities for other countries. NPJ Digit Med. 2020;3(1):94. https://doi.org/10.1038/s41746-0200306-7.

78. Ohannessian R, Yaghobian S, Duong TA, et al. France is the first country to reimburse tele-expertise at a national level to all medical doctors. Telemed e-Health. 2020;27(4):378-81. https://doi.org/ $10.1089 /$ tmj.2020.0083.

79. Cicchetti A, Di Brino E, Di Pilla A, et al. Analysis of the organizational models of response to Covid-19 in Italy: evidence from 32 Instant Reports. Ital J Health Technol Assess Deliv. 2021;14:Suppl. 1.

80. European Commission. Market study on telemedicine. 2018. https://ec.europa.eu/health/sites/ health/files/ehealth/docs/2018_provision_ marketstudy_telemedicine_en.pdf. Accessed 4 Apr 2021. 